\title{
ORIGINAL ARTICLE \\ An analysis of ideal and actual time to surgery after traumatic spinal cord injury in Canada
}

\author{
RA Glennie ${ }^{1}$, CS Bailey ${ }^{2}$, EC Tsai ${ }^{3}$, VK Noonan ${ }^{4,5}$, CS Rivers ${ }^{5}$, DR Fourney ${ }^{6}, \mathrm{H} \mathrm{Ahn}^{7}, \mathrm{BK} \mathrm{Kwon}^{4}$, J Paquet ${ }^{8}$, \\ B Drew ${ }^{9}$, MG Fehlings ${ }^{10}$, N Attabib ${ }^{11}$, SD Christie ${ }^{1}$, J Finkelstein ${ }^{12}$, RJ Hurlbert ${ }^{13}$, S Parent ${ }^{14}$, MF Dvorak ${ }^{4}$ \\ and the RHSCIR Network
}

\begin{abstract}
Study design: Retrospective analysis of a prospective registry and surgeon survey.
Objectives: To identify surgeon opinion on ideal practice regarding the timing of decompression/stabilization for spinal cord injury and actual practice. Discrepancies in surgical timing and barriers to ideal timing of surgery were explored.

Setting: Canada.

Methods: Patients from the Rick Hansen Spinal Cord Registry (RHSCIR, 2004-2014) were reviewed to determine actual timing of surgical management. Following data collection, a survey was distributed to Canadian surgeons, asking for perceived to be the optimal and actual timings of surgery. Discrepancies between actual data and surgeon survey responses were then compared using $\chi^{2}$ tests and logistic regression.

Results: The majority of injury patterns identified in the registry were treated operatively. ASIA Impairment Scale (AIS) C/D injuries were treated surgically less frequently in the RHSCIR data and surgeon survey (odds ratio $(O R)=0.39$ and 0.26 ). Significant disparities between what surgeons identified as ideal, actual current practice and RHSCIR data were demonstrated. A great majority of surgeons (93.0\%) believed surgery under $24 \mathrm{~h}$ was ideal for cervical AIS A/B injuries and 91.0\% for thoracic AIS A/B/C/D injuries. Definitive surgical management within $24 \mathrm{~h}$ was actually accomplished in $39.0 \%$ of cervical and $45.0 \%$ of thoracic cases.

Conclusion: Ideal surgical timing for traumatic spinal cord injury (tSCl) within $24 \mathrm{~h}$ of injury was identified, but not accomplished. Discrepancies between the opinions on the optimal and actual timing of surgery in tSCl patients suggest the need for strategies for knowledge translation and reduction of administrative barriers to early surgery.
\end{abstract}

Spinal Cord (2017) 55, 618-623; doi:10.1038/sc.2016.177; published online 18 April 2017

\section{INTRODUCTION}

There is often a sense of futility amongst care providers for individuals who have suffered an acute traumatic spinal cord injury (tSCI). Neuroprotective and neuroregenerative initiatives continue to evolve; however, no well-powered clinical trial has demonstrated an improvement in neurologic recovery and, therefore, these therapies have not been implemented in routine clinical practice. ${ }^{1-5}$

A growing body of evidence suggests that timely surgical decompression and stabilization may improve neurological recovery by reducing secondary damage. ${ }^{6-10}$ When one of the only interventions to potentially improve neurological outcomes in acute tSCI is early treatment, ensuring this knowledge is accepted and then translated into action is known as knowledge translation. The stages of knowledge translation have been described by many, but generally represent identification and research, analysis of context and barriers, knowledge transfer interventions, and finally utilization of the knowledge. ${ }^{11}$
The goal of this study was to assess the knowledge gap between what is known by surgeons regarding the optimal timing of surgery and what is done in practice. Finally, we sought some subjective surgeon assessment of the barriers to surgery at the ideal time.

\section{MATERIALS AND METHODS}

We proposed to analyze the gap between optimal and actual timing of surgery using tSCI registry data recording the time from injury to surgery for specific subpopulations of injury severity and anatomic location of injury and comparing this with a survey to the same surgeons performing the surgery during this time period.

\section{Rick Hansen Spinal Cord Injury Registry data}

Study subjects were recruited from the Rick Hansen Spinal Cord Injury Registry (RHSCIR), a Canadian registry at 18 acute and 13 rehabilitation facilities, which enrolls individuals who sustain a new tSCI. The registry was initiated in 2004 to answer a priori research questions and to facilitate the implementation of best

${ }^{1}$ Combined Neurosurgical and Orthopedic Spine Program, Dalhousie University, Halifax, Nova Scotia, Canada; ${ }^{2}$ Western University, London, Ontario, Canada; ${ }^{3}$ Ottawa Hospital Research Institute, University of Ottawa, Ottawa, Ontario, Canada; ${ }^{4}$ University of British Columbia, Vancouver, British Columbia, Canada; ${ }^{5}$ Rick Hansen Institute, Vancouver, British Columbia, Canada; ${ }^{6}$ Royal University Hospital, University of Saskatchewan, Saskatoon, Saskatchewan, Canada; ${ }^{7}$ St. Michael's Hospital, University of Toronto Spine Program, Toronto, Ontario, Canada; ${ }^{8}$ Hôpital de L'Enfant-Jésus, Laval University, Quebec City, Quebec, Canada; ${ }^{3}$ Hamilton Health Sciences, McMaster University, Hamilton, Ontario, Canada; ${ }^{10}$ Division of Neurosurgery and Spinal Program, University of Toronto, Toronto, Ontario, Canada; ${ }^{11}$ Horizon Health Network, Dalhousie University, Saint John Regional Hospital, Saint John, New Brunswick, Canada; ${ }^{12}$ Sunnybrook Hospital, University of Toronto, Toronto, Ontario, Canada; ${ }^{13}$ University of Calgary Spine Program, Calgary, Alberta, Canada and ${ }^{14}$ Hôpital du Sacré-Cœur de Montréal, Hôpital Ste-Justine, Université de Montréal, Montréal, Quebec, Canada

Correspondence: Professor MF Dvorak, Department of Orthopaedics, University of British Columbia, 6th Floor, Blusson Spinal Cord Centre, 818 West 10th Avenue, Vancouver V5Z 1M9, British Columbia, Canada.

E-mail: Marcel.Dvorak@ubc.ca

Received 17 March 2016; revised 19 September 2016; accepted 21 October 2016; published online 18 April 2017 
practices. All RHSCIR sites obtained local Research Ethics Board (REB) approval before enrolling participants. Any person over the age of majority who is treated at a RHSCIR site for a new tSCI is eligible for inclusion. A core data set is collected on all RHSCIR participants and a detailed data set is collected on participants who can be approached during their hospital stay and provide informed consent. For the purposes of this study, only participants who provided consent and who had a final complete registry record were included in the analysis. Details on the RHSCIR data set have been described elsewhere. ${ }^{12}$

Injury factors. A detailed neurological assessment was performed at admission according to accepted international standards (International Standards for the Neurological Classification of Spinal Cord Injury (ISNCSCI)), ${ }^{13}$ including neurological level and the ASIA Impairment Scale (AIS) which measures severity of spinal cord injury from A (most severe) to D (least severe). Injury mechanism (fall versus other) and energy of injury (high/low) were obtained. Injuries were matched to the specific level and severity of injury according to the clinical scenarios included in the surgeon survey.

Management. Whether or not acute surgery was performed, time from injury to surgery, and total hospital length of stay (inpatient acute/rehabilitation) were obtained.

Analysis cohort. Participants with cervical (C1-T1) and thoracic (T2-T10) injuries of any severity (AIS A-D) of injury with known acute surgical status (received acute surgery yes or no) were included in the analysis. Injuries from T11 to L1 were excluded given the mixed nature of their injury pattern (SCI, cauda equina injury or conus injuries).

\section{Surgeon survey}

A survey asking surgeons about ideal versus actual timing of surgical treatment for patients with tSCI was developed by a working group of 5 RHSCIR surgeon investigators (Supplementary Appendix 1). The survey contains four patient case examples and surgeons were asked to report both what they deemed would be ideal time from injury to surgery and in what time these patients would actually receive surgical treatment in their center. They were also asked to provide their subjective view of what barriers exist in their particular center to providing surgical treatment at ideal times. Respondents were also asked to provide demographic information on surgical sub-specialty, years of experience as a surgeon, and number of acute tSCI patients admitted to their site/year. The survey was administered in early 2013 to the surgeon investigators contributing data to the RHSCIR, and the spine surgeon membership of Canadian Spine Society.

The injury strata for analysis were as follows:

(a) Cervical (C1-T1) AIS A/B (questions 4 and 5 on the survey; see Supplementary file)

(b) Cervical AIS C (question 7);

(c) Cervical AIS D (question 8);

(d) Thoracic (T2-T10) AIS A/B/C/D (questions 9-11).

These were chosen to match the survey questionnaire as closely as possible. Note that as questions are combined for group a and d, the total number of responses are 62 and 93, respectively, from the 31 surgeons for the current surgical details. One respondent did not answer questions regarding ideal timing of surgical treatment so the denominator for each timing question was 30 .

\section{Statistical methods}

All analyses were performed using SAS 9.3/9.4 (SAS Institute Inc., Cary, NC, USA). Frequency and percentage were provided for categorical variables and $n$, mean, maximum, minimum and s.d. were provided for numerical variables. Chi-square tests were used to see whether or not there is a significant difference of surgery rates among the overall injury strata (defined above) and the odds ratio estimate and confidence intervals (obtained from logistic regression model) evaluated whether or not the odds of doing surgery is significant in each pairwise comparison.

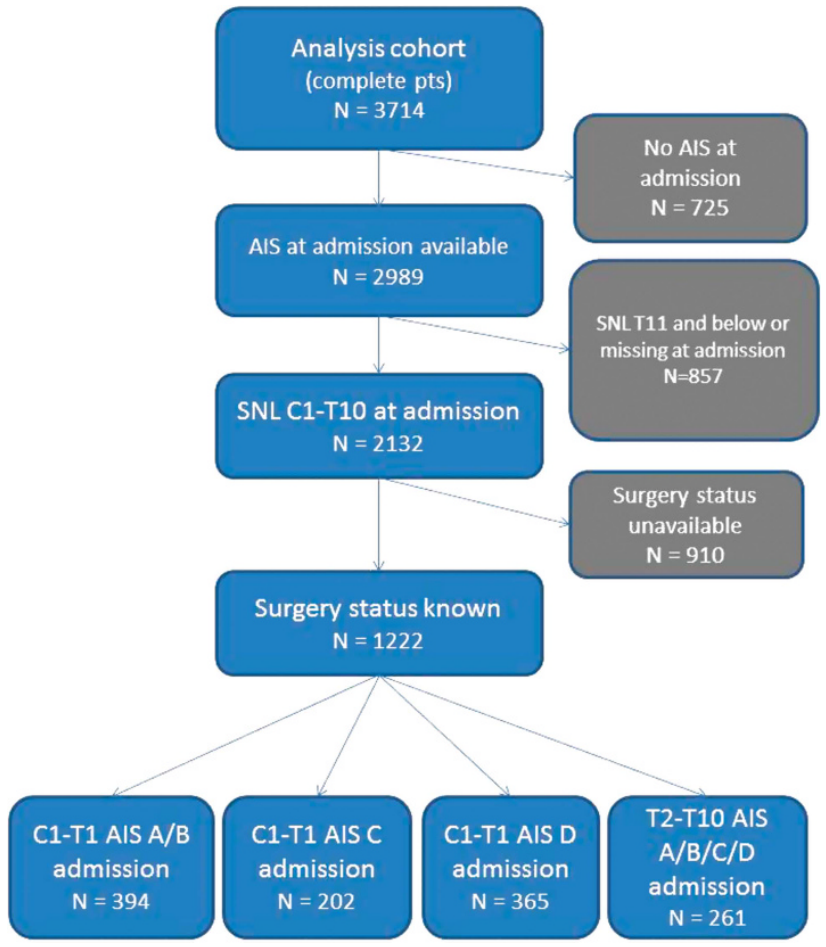

Figure 1 CONSORT flow diagram of analysis cohort.

\section{RESULTS}

\section{RHSCIR data}

A total of 1222 RHSCIR participants were included in the analysis (Figure 1). Baseline participant demographics are reported in Table 1. Participants were grouped as per the survey clinical scenarios (Table 1).

\section{Surgeon survey demographic results}

Survey responses were received from 31 spine surgeons from the 18 acute registry sites; $16(51.6 \%)$ were orthopedic and $15(48.4 \%)$ were neurosurgeons. Mean experience was 14 years (median: 8, range: 1-40). All authors completed the survey, and the surgeons who responded treated roughly $70.0 \%$ of the participants included in the RHSCIR. Note one surgeon did not answer all of the questions on ideal practice, so there were only 30 responses for each relevant survey question.

\section{Surgery versus no surgery: surgeon survey and actual surgical practice}

See Table 2 for details of surgeon actual/ideal responses regarding surgical treatment compared with RHSCIR data.

Cervical AIS $A / B$ injuries. Surgeon survey results were unanimous (that is, $100.0 \%$ of surgeons) in their preferred treatment of patients with cervical AIS A/B injuries, with all surgeons responding that they treat this injury operatively and that the ideal treatment option is to treat this injury operatively. Looking at the actual RHSCIR data, however, patients were not all treated with surgery; 363 patients out of a total of $394(92.1 \%)$ with AIS A/B injuries were treated surgically.

Cervical AIS C injuries. A similar trend was found in cervical AIS C patients where the majority of surgeons (29/31) felt that they would 
typically treat this injury surgically $93.5 \%$ of the time, whereas surgeons felt this injury would ideally be surgical intervention in 96.7\% of cases (30/31). In actual RHSCIR data, cervical AIS C patients were treated surgically in $82.2 \%$ of cases (166 out of 202 AIS C cases).

Cervical AIS D injuries. Surgeons felt that cervical AIS D injuries were only treated with surgery $74.2 \%$ of the time in their practice, and similarly surgeons felt surgical intervention was the ideal practice $77.4 \%$ of the time. The raw data is similar for this injury category, where $75.1 \%$ of patients in the RHSCIR cohort with AIS D injuries underwent surgery.

Thoracic AIS $A / B / C / D$ injuries. No surgeons reported treating thoracic injuries non-operatively in their practice, and most surgeons

\section{Table 1 Participant demographics and injury characteristics} $(n=1222)$

\begin{tabular}{|c|c|}
\hline Age: mean (range) & $\begin{array}{c}47.4 \text { (s.d. }=18.7 \\
\min =12, \max =92)\end{array}$ \\
\hline Male gender; $n$ & $976(80.0 \%)$ \\
\hline \multicolumn{2}{|l|}{ Neurological category (international standards) } \\
\hline C1-C4, AIS A, B, C & $285(23.3 \%)$ \\
\hline C5-C8, AIS A, B, C & $298(24.4 \%)$ \\
\hline T1-S5, AIS A, B, C & $254(20.8 \%)$ \\
\hline All, AIS D & $385(31.5 \%)$ \\
\hline \multicolumn{2}{|l|}{ Neurological category (survey categories) } \\
\hline C1-T1, AIS A, B & $394(21.2 \%)$ \\
\hline $\mathrm{C} 1-\mathrm{T} 1, \mathrm{AIS} \mathrm{C}$ & $202(16.5 \%)$ \\
\hline $\mathrm{C} 1-\mathrm{T} 1, \mathrm{AIS} \mathrm{D}$ & $365(29.9 \%)$ \\
\hline T2-T10, AIS A, B, C, D & $261(21.4 \%)$ \\
\hline Had surgery; $n$ & $1050(85.9 \%)$ \\
\hline Time from injury to surgery unknown/missing & $114(10.9 \%)$ \\
\hline Time from injury to surgery known include outlier ${ }^{a}$ & $936(89.1 \%)$ \\
\hline Time from injury to surgery (h); mean (s.d.) & 100.8 (s.d. $=411.7$ ) \\
\hline Time from injury to surgery known exclude outlier & $927(88.3 \%)$ \\
\hline Time from injury to surgery (h); mean (s.d.) & 69.4 (s.d. = 126.7) \\
\hline Surgery $<12 \mathrm{~h}$ from injury & $126(13.6 \%)$ \\
\hline Surgery $12-24 \mathrm{~h}$ from injury & $245(26.4 \%)$ \\
\hline Surgery 24-72 h from injury & $362(39.1 \%)$ \\
\hline Surgery $>72 \mathrm{~h}$ from injury & $194(20.9 \%)$ \\
\hline Total hospital length of stay (days); mean (s.d.) & 148.3 (s.d. $=108.3$ ) \\
\hline
\end{tabular}

Abbreviation: AIS, ASIA Impairment Scale.

a Outliers are defined as patients with time to surgery $>1162 \mathrm{~h}$ (99th percentile). Total length

of stay represents days of inpatient acute/rehabilitation care. felt surgical intervention was an ideal practice $96.8 \%$ of the time; only one surgeon $(3.2 \%)$ replied they considered conservative treatment ideal, despite reporting that actual practice at their site was surgical treatment. The patient data demonstrated high surgical rates with $94.6 \%$ of patients undergoing definitive surgical management.

\section{Logistic regression analysis: surgery versus no surgery}

The $\chi^{2}$ test result $(P$-value $<0.0001)$ suggests that there were significant differences in the rates of patients in the RHSCIR cohorts who were actually treated surgically as opposed to those treated non-operatively between the various severities and anatomical locations of injury. Logistic regression modeling, which is fitted on the probability of receiving surgery and considering neurology at admission as covariate (all compared to patients with cervical AIS $\mathrm{A} / \mathrm{B}$ patients), demonstrated that patients with cervical $\mathrm{C}$ injuries had a reduced odds of undergoing surgical management (odds ratio $(\mathrm{OR})=0.39,0.23-0.6695 .0 \%$ confidence interval $(\mathrm{CI}))$. Cervical AIS $\mathrm{D}$ patients were even less likely to undergo surgical management for their injuries $(\mathrm{OR}=0.26,0.16-0.39,95.0 \% \mathrm{CI})$. There was no difference in the odds of undergoing surgery when comparing cervical AIS $A / B$ injuries versus those with thoracic $A / B / C / D$ injuries $(O R=$ $1.51,95.0 \%$ CI $0.68-2.98)$. Both these injury patterns had high rates $(92.1 \%$ and $94.6 \%)$ of surgical management.

\section{Timing to surgical decompression: survey and RHSCIR data} See Table 3 for complete surgeon actual/ideal survey responses on time to surgery compared with RHSCIR data in various time frames. In the RHSCIR data, patients with time to surgery $>1162 \mathrm{~h}$ (99th percentile) were considered outliers and excluded from the analysis.

Cervical AIS $A / B$ injuries. This category is comprised out of two survey questions, so there are 62 responses from 31 surgeons. Seventeen of the 62 responses $(27.4 \%)$ claimed that surgical treatment within $12 \mathrm{~h}$ was current practice for cervical AIS A/B injuries. The majority (33/61 responses or $55.0 \%$ ) felt that this injury should ideally be treated surgically within $12 \mathrm{~h}$. This represents a $27.6 \%$ difference between what surgeons report as their current practice and what they feel the ideal surgical practice would be. The RHSCIR data set demonstrates that only $67 / 330$ (20.3\%) of patients with cervical AIS $\mathrm{A} / \mathrm{B}$ injuries were actually treated with surgery within the 12-h window. Comparing questionnaire and actual RHSCIR data, this suggests that $34.7 \%$ of patients are not receiving ideal timely care.

Out of the 61 responses, surgeons felt that they treated cervical AIS $\mathrm{A} / \mathrm{B}$ injuries within the 24 -h mark in their current practice $(57.3 \%)$. Surgeons strongly felt that these injuries should be ideally receiving surgical intervention within $24 \mathrm{~h}$ with $93.3 \%$ of responses. RHSCIR

Table 2 RHSCIR and surgeon survey data for sample scenarios ( $n, \%)$

\begin{tabular}{|c|c|c|c|c|c|c|}
\hline \multirow[t]{3}{*}{ Neurology at admission } & \multicolumn{2}{|c|}{ RHSCIR } & \multicolumn{4}{|c|}{ Survey } \\
\hline & \multirow{2}{*}{ Surgery $=$ yes $(\mathrm{n}=1050 ; \%)$} & \multirow{2}{*}{ Surgery $=n o(n=172 ; \%)$} & \multicolumn{2}{|c|}{ Surgery $=$ yes } & \multicolumn{2}{|c|}{ Surgery $=$ no } \\
\hline & & & Actual (\%) & Ideal (\%) & Actual (\%) & Ideal (\%) \\
\hline $\mathrm{AIS}=\mathrm{A} / \mathrm{B}, \mathrm{SNL}=$ cervical & $363(92.1)$ & $31(7.9)$ & $31(100)$ & $31(100)$ & $0(0)$ & $0(0)$ \\
\hline AIS C, SNL = cervical & $166(82.2)$ & $36(17.8)$ & $29(93.5)$ & $30(96.8)$ & $2(6.5)$ & $1(3.2)$ \\
\hline $\mathrm{AIS}=\mathrm{D}, \mathrm{SNL}=$ cervical & $274(75.1)$ & $91(24.9)$ & $23(74.2)$ & $24(77.4)$ & $8(25.8)$ & $7(22.6)$ \\
\hline AIS $A / B / C / D, S N L=$ thoracic & $247(94.6)$ & $14(5.4)$ & $31(100)$ & $30(96.8)$ & $0(0)$ & $1(3.2)$ \\
\hline
\end{tabular}

Abbreviations: AIS, ASIA Impairment Scale; SNL, single neurological level. 
Table 3 Surgeon survey responses for current actual (31 respondents) and ideal (30 respondents) timing to definitive surgical management compared to RHSCIR data (for those who had surgery)

\begin{tabular}{|c|c|c|c|c|c|c|}
\hline \multirow[t]{2}{*}{ Injury (AIS) } & \multirow[t]{2}{*}{ Time to definitive surgery (h) } & \multicolumn{2}{|c|}{ Survey } & \multicolumn{3}{|r|}{ RHSCIR } \\
\hline & & Actual (\%) & Ideal (\%) & $\%$ & $\mathrm{n}$ & \\
\hline \multirow[t]{4}{*}{ Cervical A/B } & $<12$ & 27.4 & 55.0 & 20.3 & 67 & $\begin{array}{c}\text { Cervical A/B, } n=394, n=63 \mathrm{u} / \mathrm{k} \\
\text { Outlier, } n=1 \\
\text { Analysis, } n=330\end{array}$ \\
\hline & $12-24$ & 29.0 & 38.3 & 31.5 & 104 & \\
\hline & $24-72$ & 29.0 & 1.7 & 35.8 & 118 & \\
\hline & $>72$ & 6.5 & 0.0 & 12.4 & 41 & \\
\hline \multirow[t]{4}{*}{ Cervical C } & $<12$ & 12.9 & 33.3 & 9.8 & 14 & $\begin{array}{c}\text { Cervical C, } n=202, n=56 \mathrm{u} / \mathrm{k} \\
\text { Outlier, } n=3 \\
\text { Analysis, } n=143\end{array}$ \\
\hline & $12-24$ & 38.7 & 36.7 & 25.2 & 36 & \\
\hline & $24-72$ & 22.6 & 26.7 & 43.4 & 62 & \\
\hline & $>72$ & 19.4 & 0.0 & 21.7 & 31 & \\
\hline \multirow[t]{4}{*}{ Cervical D } & $<12$ & 6.5 & 16.7 & 7.1 & 17 & $\begin{array}{c}\text { Cervical } \mathrm{D}, n=365, n=125 \mathrm{u} / \mathrm{k} \\
\text { Outlier, } n=2 \\
\text { Analysis, } n=238\end{array}$ \\
\hline & $12-24$ & 25.8 & 33.3 & 15.1 & 36 & \\
\hline & $24-72$ & 22.6 & 16.7 & 39.1 & 93 & \\
\hline & $>72$ & 19.4 & 10.0 & 38.7 & 92 & \\
\hline \multirow[t]{4}{*}{ Thoracic A/B/C/D } & $<12$ & 21.5 & 48.9 & 13.0 & 28 & $\begin{array}{c}\text { Thoracic A/B/C/D, } n=261, n=42 \mathrm{u} / \mathrm{k} \\
\text { Outlier, } n=3 \\
\text { Analysis, } n=216\end{array}$ \\
\hline & $12-24$ & 49.5 & 42.2 & 31.9 & 69 & \\
\hline & $24-72$ & 24.7 & 7.8 & 41.2 & 89 & \\
\hline & $>72$ & 4.3 & 0.0 & 13.9 & 30 & \\
\hline
\end{tabular}

Abbreviations: AIS, ASIA Impairment Scale; RHSCIR, Rick Hansen Spinal Cord Injury Registry; u/k, unknown/missing.

Note that the calculations reflect the number of total responses: the cervical AIS A/B group data were compiled from two survey questions, cervical AIS C from one survey question, cervical AIS D from one survey question and thoracic AIS A/B/C/D compiled from three survey questions.

Outliers are defined as time to surgery $>1162 \mathrm{~h}$ (99th percentile).

data demonstrate that only $171 / 330$ patients (51.8\%) with these injuries were treated within this ideal time frame.

The survey demonstrated that surgeons felt they were treating cervical AIS A/B injuries in between 24 and $72 \mathrm{~h} 29.0 \%$ of the time. Only $1.7 \%$ of surgeon responses indicated this as an ideal time for definitive surgical management. Actual data demonstrate that $118 / 330$ $(35.8 \%)$ of these injuries are treated within this time frame. This demonstrates that $34.1 \%$ of these patients are not being treated in the ideal time frame.

Surgeons reported that cervical AIS injuries were currently being treated at more than $72 \mathrm{~h} 6.5 \%$ of the time; no surgeons described this as being the ideal time frame to treat these injuries. RHSCIR data suggest that $41 / 330(12.4 \%)$ of patients were treated within this time interval.

Cervical AIS C injuries. The survey data suggest that $12.9 \%$ of surgeons felt that they actually treated this injury in $<12 \mathrm{~h}$, whereas $33.3 \%$ of surgeons indicated this to be an ideal time frame. RHSCIR data suggested that $14 / 143(9.8 \%)$ of patients were actually treated within this time frame. This demonstrates a $23.5 \%$ difference between what surgeons identify as ideal surgical management practice and what actually occurs within the RHSCIR data set.

Cervical AIS D injuries. Only 2 of 31 surgeons (6.5\%) felt that cervical AIS D injuries are actually treated within the 12 -h time period.
Five $(16.7 \%)$ felt that they should ideally be treated within this time frame. Actual RHSCIR data suggest that $7.1 \%$ of these patients are treated within $12 \mathrm{~h}$ after their injury.

Six surgeons (19.4\%) felt that they would typically treat the majority of these injuries after the 72 -h mark. Three surgeons (10.0\%) felt that these injuries were ideally treated in this time frame. RHSCIR data suggest that 92/238 (38.7\%) of these injuries are actually treated after $72 \mathrm{~h}$. This shows that a number of these injuries $(28.7 \%)$ are being treated later than what surgeons would identify as ideal.

Thoracic AIS $A / B / C / D$ injuries. Surgeons reported that they would typically treat these injuries within $24 \mathrm{~h} 71.0 \%$ of the time. Surgeons reported that surgical treatment of these injuries within $24 \mathrm{~h}$ of injury would be ideal practice $91.1 \%$ of the time. RHSCIR data suggest that these injuries were treated within $24 \mathrm{~h}$ for only 97 out of 216 patients (45.0\%). This data demonstrates that not only were surgeons inaccurate in describing their current practice by $26.0 \%$ but the data set demonstrates that $46.1 \%$ of patients are not receiving treatment within an acceptable 24-h interval.

\section{Barriers to appropriate surgical timing}

Surgeons identified a number of barriers to timely treatment of patients with $\mathrm{tSCI}$ from the survey. The most common reasons for delay in treatment were as follows: operating room availability 


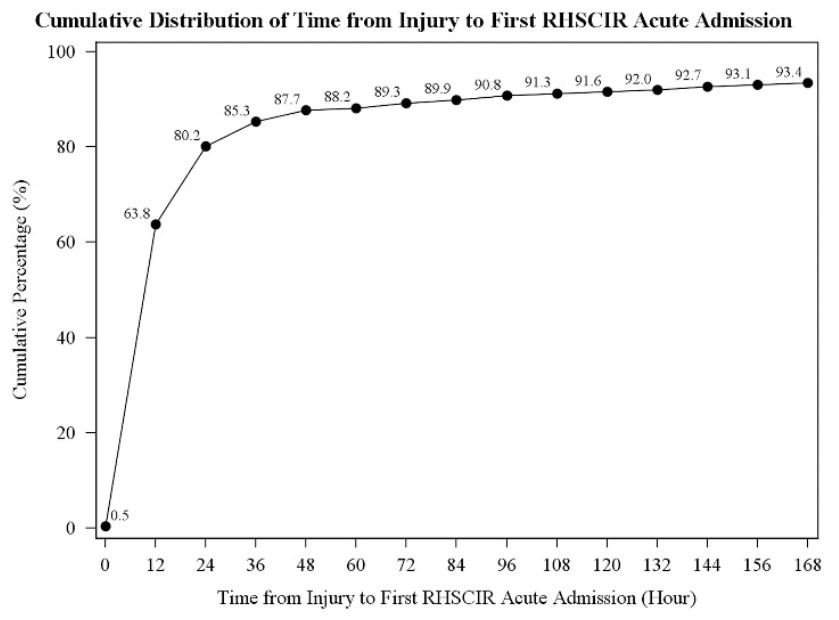

Figure 2 Time from injury to admission to a RHSCIR acute care site.

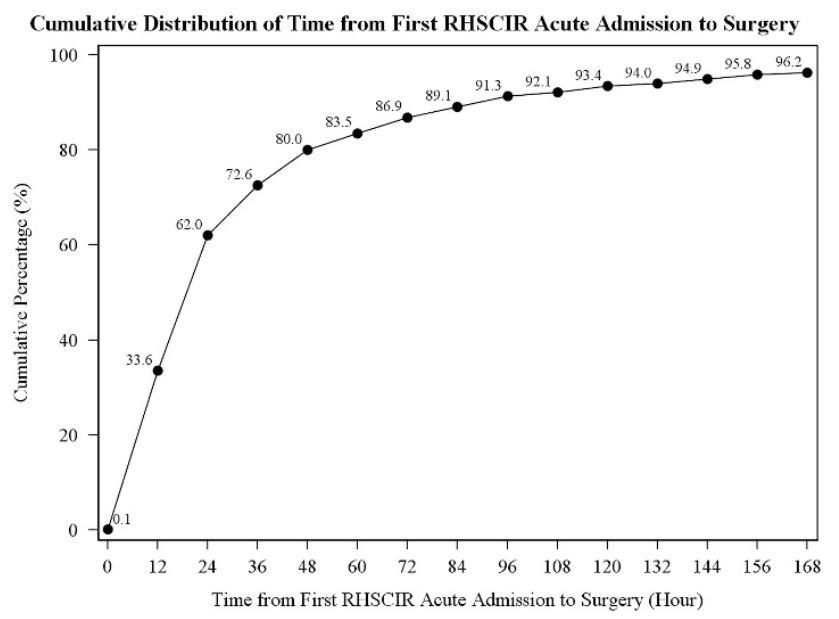

Figure 3 Time from admission to surgery.

(52.0\%), transport of patients from place of injury or other centers $(28.0 \%)$, medical condition of patients $(7.0 \%)$, lack of specialized operating room nursing team $(3.0 \%)$, and lack of surgeon availability on call $(3.0 \%)$.

Using the RHSCIR data set, we were able to determine how long patients took to be transferred to the acute care site and after admission, determine the time to surgery. These time intervals give a general idea about time for transfer and time in hospital awaiting surgery. Overall, $64.0 \%$ of patients were transferred to the acute site within $12 \mathrm{~h}$ of their injury, and $80.0 \%$ were transferred within $24 \mathrm{~h}$. Please see Figure 2 for full injury to admission time details. Once patients were admitted, only $34.0 \%$ of patients were treated surgically within $12 \mathrm{~h}$ and only $62.0 \%$ were treated within $24 \mathrm{~h}$. Please see Figure 3 for average time from admission to surgery.

\section{DISCUSSION}

Delivering timely surgical care to spinal cord injury patients appears to be one of the few therapeutic interventions that may influence neurological recovery, lead to better outcomes and also has the opportunity to reduce the morbidity and the healthcare costs associated with spinal cord injury. ${ }^{6,8,14,15}$ The results of our survey suggest achieving surgical decompression and stabilization within $24 \mathrm{~h}$ from the time of injury is most desirable. The results from the RHSCIR data set demonstrate that there is disparity in what surgeons identify as ideal surgical practice and what actually occurs.

The greatest areas of knowledge gap is the discrepancies in which cervical AIS A/B and thoracic AIS A/B/C/D injuries were treated. Although considerable discrepancy exists with the actual and ideal treatment for these injury patterns within the 12-h window, it may not be possible to accomplish this practically given transport, initial patient evaluation and imaging requirements. If we assume this but accept that these factors should be adequately addressed within the 24-h time frame, we continue to see a significant discrepancy. For example, $94.0 \%$ of surgeons reported that definitive surgical management for cervical AIS A/B injuries within $24 \mathrm{~h}$ was ideal. The RHSCIR data suggest that this is only accomplished $52.0 \%$ of the time, or in 171 out of 330 patients. Thus, 159 patients with this injury pattern did not receive timely surgical management or what was identified as ideal by surgeons.

A similar trend can be found with thoracic AIS A/B/C/D injuries. In this injury pattern, not only is there a discrepancy between actual and ideal timing, but surgeons are accomplishing timely definitive surgical management $26.0 \%$ less often than they believe. Here, a significant gap exists not only with knowledge transfer interventions, but also represents a lack of awareness or context by surgeons. Two steps in the knowledge translation process are deficient with regard to timely treatment of this injury.

Roughly a third of respondents identified transportation of patients as a major contributing factor to slower management times. Transportation issues are a reality of living in Canada due to the vast geography and rural areas; however, a great majority of patients $(80.0 \%)$ are transferred before the 24 -h mark. A number of networks have been established across the county for 'life or limb' scenarios and spinal cord injuries are often, if not always, considered in this fashion. Even given this highest priority, however, expedited transport continues to be an issue due to geographically remote locations that are only accessible by fixed wing aircraft and may be affected by unpredictable weather patterns.

What is more striking is the proportion of patients having surgery within $24 \mathrm{~h}$ of arrival to an acute care site. Only $62.0 \%$ of patients undergo surgical management within $24 \mathrm{~h}$. Overall, surgeons expressed significant frustration with lack of operating room availability (52.0\%). This is likely to be a main contributor to delays in addition to patient stabilization and access to appropriate diagnostic testing.

In Canada, it can be very hard to shape and change funding allocation without well-designed, compelling studies that demonstrate better outcomes for patients. $5,6,14$ The results of the RHSCIR registry data and the surgeon survey clearly show that we are not meeting what are currently accepted benchmarks based on the best available evidence. Combining registry data and professional opinion represents the best available evidence relative to the timing of surgery in this traumatically-injured patient population.

\section{Limitations}

Identifying specific injury patterns in the database is challenging given the clinical heterogeneity of tSCI. For example, a cervical fracture dislocation with little preserved motor function can be grouped in the same category as a central cord injury patient with more preserved motor function (cervical AIS C). In addition, the current analysis did not take into consideration any information about morphology, mechanism of injury, osteoporotic compression fractures, and so on. The optimal techniques, approach, and procedures related to surgical 
treatment for spinal cord injury vary widely and are beyond the scope of the current study. Within the categories of tSCI, incomplete cervical injuries (commonly referred to as central cord injuries) highlight this controversy, and so, including this injury pattern in the current analysis may be seen as inappropriate. This may partially explain the slower times to surgical management for cervical AIS C and D patients in this analysis as many surgeons have adopted a 'watch and wait' approach to some of these incomplete injuries. This may also explain why more of the AIS C and D injuries were occasionally treated nonsurgically as there can be injury morphologies that do not demonstrate any ongoing instability and ongoing compression on the spinal cord. In addition, further stratifying thoracic injuries based on the severity of neurologic injury and morphological details would help further explore the preferences of surgeons, but was not possible given the existing questionnaire design.

\section{CONCLUSION}

Our registry data suggest that we are not meeting the goal of early surgery. Operating room access and urgent patient transport appear to be pertinent barriers. Future study should be aimed at identifying specific centers achieving urgent surgical goals so that these strategies can be replicated at other institutions.

\section{DATA ARCHIVING}

There were no data to deposit.

\section{CONFLICT OF INTEREST}

The authors declare no conflict of interest.

\section{ACKNOWLEDGEMENTS}

We would like to thank the RHSCIR network and all the participating local RHSCIR sites: GF Strong Rehabilitation Centre, Vancouver General Hospital, Foothills Hospital, Glenrose Rehabilitation Hospital, Royal Alexandra Hospital, University of Alberta Hospital, Royal University Hospital, Saskatoon City Hospital, Winnipeg Health Sciences Centre, Toronto Western Hospital, Toronto Rehabilitation Institute, St. Michael's Hospital, Sunnybrook Health Sciences Centre, Hamilton General Hospital, Hamilton Health Sciences Regional Rehabilitation Centre, Victoria Hospital, University Hospital, Parkwood Hospital, The Ottawa Hospital Rehabilitation Centre, The Ottawa Hospital Civic Campus, Hôpital de L'Enfant-Jésus, Institut de réadaptation en déficience physique de Québec, Centré de réadaptation Lucie-Bruneau, Institut de réadaptation Gingras-Lindsay-de-Montréal, Hôpital du Sacré Cœur de Montréal, Nova Scotia Rehabilitation Centre, QEII Health Sciences Centre, Saint John Regional Hospital, Stan Cassidy Centre for Rehabilitation, St. John's Health Sciences Centre and L.A. Miller Rehabilitation Centre.
1 Blight AR. Miracles and molecules-progress in spinal cord repair. Nat Neurosci 2002; 5 (Suppl 11): 1051-1054.

2 Mothe AJ, Tator $\mathrm{CH}$. Advances in stem cell therapy for spinal cord injury. J Clin Invest 2012; 122: 3824-3834.

3 Tator $\mathrm{CH}$. Review of treatment trials in human spinal cord injury: issues, difficulties, and recommendations. Neurosurgery 2006; 59: 957-982 discussion 82-87.

4 Tator $\mathrm{CH}$, Hashimoto R, Raich A, Norvell D, Fehlings MG, Harrop JS et al. Translational potential of preclinical trials of neuroprotection through pharmacotherapy for spinal cord injury. J Neurosurg Spine 2012; 17: 157-229.

5 Wilson JR, Forgione N, Fehlings MG. Emerging therapies for acute traumatic spinal cord injury. CMAJ 2013; 185: 485-492.

6 Fehlings MG, Vaccaro A, Wilson JR, Singh A, Cadotte DW, Harrop JS et al. Early versus delayed decompression for traumatic cervical spinal cord injury: results of the Surgical Timing in Acute Spinal Cord Injury Study (STASCIS). PLOS ONE 2012; 7: e32037.

7 O'Boynick CP, Kurd MF, Darden BV 2nd, Vaccaro AR, Fehlings MG. Timing of surgery in thoracolumbar trauma: is early intervention safe? Neurosurg Focus 2014; 37: E7.

8 van Middendorp JJ, Hosman AJ, Doi SA. The effects of the timing of spinal surgery after traumatic spinal cord injury: a systematic review and meta-analysis. I Neurotrauma 2013; 30: 1781-1794.

9 Werndle MC, Saadoun S, Phang I, Czosnyka M, Varsos GV, Czosnyka ZH et al. Monitoring of spinal cord perfusion pressure in acute spinal cord injury: initial findings of the injured spinal cord pressure evaluation study. Crit Care Med 2014; 42: 646-655.

10 Wilson JR, Fehlings MG. Emerging approaches to the surgical management of acute traumatic spinal cord injury. Neurotherapeutics 2011; 8: 187-194.

11 Ward V, House A, Hamer S. Developing a framework for transferring knowledge into action: a thematic analysis of the literature. J Health Serv Res Policy 2009; 14: $156-164$.

12 Noonan VK, Kwon BK, Soril L, Fehlings MG, Hurlbert RJ, Townson A et al. The Rick Hansen Spinal Cord Injury Registry (RHSCIR): a national patient-registry. Spinal Cord 2011; 50: 22-27.

13 Waring WP III, Biering-Sorensen F, Burns S, Donovan W, Graces D, Jha A et al. 2009 Review and revisions of the International Standards for the Neurological Classification of Spinal Cord Injury. J Spinal Cord Med 2010; 33: 346-352.

14 Bourassa-Moreau E, Mac-Thiong JM, Feldman DE, Thompson C, Parent S. Non-neurological outcomes after complete traumatic spinal cord injury: the impact of surgical timing. J Neurotrauma 2013; 30: 1596-1601.

15 Furlan JC, Tung K, Fehlings MG. Process benchmarking appraisal of surgical decompression of spinal cord following traumatic cervical spinal cord injury: opportunities to reduce delays in surgical management. J Neurotrauma 2013; 30 : 487-491.

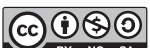

This work is licensed under a Creative Commons Attribution-NonCommercial-ShareAlike 4.0 International License. The images or other third party material in this article are included in the article's Creative Commons license, unless indicated otherwise in the credit line; if the material is not included under the Creative Commons license, users will need to obtain permission from the license holder to reproduce the material. To view a copy of this license, visit http://creativecommons.org/licenses/bync-sa/4.0/

(C) The Author(s) 2017

Supplementary Information accompanies this paper on the Spinal Cord website (http://www.nature.com/sc). 